\title{
Postnatal Development of Synchronized Network Oscillations in the Ferret Dorsal Lateral Geniculate and Perigeniculate Nuclei
}

\author{
David A. McCormick, ${ }^{1}$ Francine Trent, and Ary S. Ramoa ${ }^{2}$ \\ 'Section of Neurobiology, Yale University School of Medicine, New Haven, Connecticut 06510 and 'Department of \\ Anatomy, Medical College of Virginia, Virginia Commonwealth University, Richmond, Virginia 23298-0709
}

Extracellular and intracellular recordings from slices of ferret dorsal lateral geniculate nucleus (LGNd) at postnatal ages $\mathrm{P} 10-53$ were performed to examine the postnatal development of spindle waves and the ability of block of GA$B A_{A}$ receptors to alter these spindle waves into a slower, synchronous oscillation. As in prior studies in the adult, intracellular and extracellular recordings at ages P33-53 revealed robust spindle waves to be present in both the LGNd and perigeniculate nucleus (PGN). Intracellular recordings from thalamocortical relay cells in the A-laminae of the LGNd revealed that these cells received repetitive inhibitory postsynaptic potentials (IPSPs) at 6-9 Hz during the generation of spindle waves, and generated rebound low threshold $\mathrm{Ca}^{2+}$ spikes and bursts of 2-6 action potentials following each second or third IPSP. Intracellular recordings from the GABAergic neurons of the PGN at P3353 revealed barrages of EPSPs that activated low threshold $\mathrm{Ca}^{2+}$ spikes and high frequency burst discharges of 2-10 action potentials during spindle wave generation. In contrast, full spindle waves were absent at ages prior to approximately P22 and spindle waves between the ages of P26 and approximately P30 were relatively weak and associated with only one or two action potentials per burst in both PGN neurons and LGNd relay cells. Bath application of the GABA $_{A}$ antagonist bicuculline methiodide at P41-53 resulted in a conversion of normal spindle waves into a marked 2-4 $\mathrm{Hz}$ oscillation in which the action potential firing of both thalamocortical relay and PGN neurons was greatly increased. In contrast, block of GABA receptors prior to age P39 did not result in the generation of the slowed, 2-4 Hz network oscillation.

Investigation of the electrophysiological properties of PGN neurons revealed that the postnatal development of spindle waves and bicuculline-induced slow oscillations were associated with an increase in the ability of PGN neurons to generate high frequency bursts of action potentials, suggesting that these changes in electrophysiological properties may contribute to the late development of synchronized oscillations in the ferret LGNd.

[Key words: oscillation, dorsal lateral geniculate, thalamus, development, epilepsy, absence seizure]

Received Mar. 8, 1995; revised Apr. 10, 1995; accepted Apr. 12, 1995.

This work was supported by the NIH, the Klingenstein Fund, and the Sloan Foundalion.

Correspondence should be addressed to David A. McCormick, Section of Neurobiology, Yale University School of Medicine, 333 Cedar Street, New Haven, CT 06510.

Copyright (C) 1995 Society for Neuroscience $\quad 0270-6474 / 95 / 155739-14 \$ 05.00 / 0$
Spindle waves are a form of synchronous oscillation characterized by brief ( $1-3 \mathrm{sec}$ ) periods of $7-15 \mathrm{~Hz}$ rhythmic activity in the electroencephalogram (EEG) during periods of drowsiness and slow wave sleep. Spindle waves are generated in the thalamus and involve an interaction between GABAergic neurons and thalamocortical relay cells (Andersen and Andersson, 1968; Steriade and Deschênes, 1984; Steriade et al., 1993; von Krosigk et al., 1993). Rhythmic burst firing in the GABAergic neurons of the nucleus reticularis thalami $(\mathrm{nRt})$ or the perigeniculate nucleus (PGN) induces in thalamocortical relay cells rhythmic inhibitory postsynaptic potentials, some of which are followed by rebound low threshold $\mathrm{Ca}^{2+}$ spikes and bursts of action potentials (Steriade et al., 1985, 1987, 1993; Bal et al., 1995a,b). This burst firing in thalamic relay cells then triggers or reinforces additional burst firing in the GABAergic nRt/PGN neurons, thus starting the cycle again. In this manner, spindle waves appear to be generated as a cyclical nctwork oscillation depending upon both the intrinsic and the synaptic characteristics of intrathalamic and thalamocortical circuits. Postnatal developmental studies of spindle wave generation in the human EEG reveal that these events do not appear until approximately 2 months after birth and strengthen over the next several months and years of age (Metcalf, 1970; reviewed in Fisch, 1991). The cellular mechanisms underlying this late appearance of spindle waves in the EEG are unknown.

Absence scizures are charactcrized in children by brief periods (typically $5-10 \mathrm{sec}$ ) of staring, occasionally associated with eye blinking, and a marked $3 \mathrm{~Hz}$ "spike-and-wave" synchronous oscillation in the EEG (Niedermeyer, 1990; reviewed in Aicardi, 1994). Data obtained from two animal models of absence seizures, the feline generalized penicillin epilepsy (FGPE) model and the generalized absence epileptic rat of Strasbourg (GEARS) model, indicate that the cellular mechanisms of spikeand-wave seizures involve those underlying the generation of spindle wave oscillations (Kostopoulos ct al., 1981a,b; Buzsaki et al., 1990; reviewed in Avoli et al., 1990). For example, in the FGPF model, intramuscular administration of high doses of penicillin are associated with a slow transformation of normal spindle waves into spike-and-wave seizures (Kostopoulos et al., 1981a,b). Extracellular single unit recordings of thalamic neurons during the generation of these spike-and-wave seizures indicate that many thalamic cells are locked into a "burst-pause" pattern associated with the "spike" and "wave" components of the scizurc (Avoli and Gloor, 1982). In addition, in the GAERS rodent model, intrathalamic injection or peripheral administration of a $\mathrm{GABA}_{\mathrm{B}}$ receptor antagonist results in a block of spikeand-wave seizures, while thalamic application of $\mathrm{GABA}_{\mathrm{B}}$ ago- 
nists exacerbates them (Hosford et al., 1992; Liu et al., 1992; Snead, 1992). Activation of $\mathrm{GABA}_{\mathrm{B}}$ receptors is especially effective in activating low threshold $\mathrm{Ca}^{2+}$ spikes in thalamic relay neurons (c.g., scc Crunelli and Leresche, 1991), an event that is important for the generation of spike-and-wave seizures.

In humans, typical absence seizures often make their first clinical appearance around 4-6 years of age (although rare cases in the first year of life have been reported), and in about half of the cases, these seizures remit during adolescence or early adulthood (reviewed in Aicardi, 1994). Continuous EEG recordings often reveal that the frequency of electrographic absence seizures increases dramatically during periods of slow wave sleep, when spindle waves normally occur, and are suppressed during rapid-eye-movement (REM) sleep, when spindle waves are absent (reviewed in Kellaway, 1985; Kellaway et al., 1990). Together, these animal and human studies suggest that the cellular mechanisms for generation of absence seizures are related to those underlying spindle wave generation and that these develop during the postnatal maturation of thalamic and thalamocortical systems.

A number of studies have demonstrated that the refinement of axonal connections in the nervous system occurs through an activity-dependent process (Archer et al., 1982; Dubin et al., 1986; Stryker and Harris, 1986; Shatz and Stryker, 1988; reviewed in Constantine-Paton et al., 1990; Shatz, 1990; Goodman and Shatz, 1993). Blocking or altering normal activity results in alteration in the refinement of both retinogeniculate connections as well as thalamocortical axons in the visual cortex. Recently, it has been suggested that the occurrence of spontaneous synchronized activity, which is known to occur in the developing retina (Galli and Maffei, 1988; Maffei and Galli-Resta, 1990), may play an important role in the establishment of proper neuronal connections within the retinogeniculate system (see Meister et al., 1991). Multisite recording from the ferret retina in vitro, for example, demonstrates waves of synchronized activity that sweep across the retina (Meister et al., 1991; Wong et al., 1993). These waves of activity may be useful for the establishment of proper axonal connections, since the degree of correlation between neighboring neurons may signal nearest neighbor relations. The possibility that similar waves of activity occur in the developing thalamocortical system has not been thoroughly examined, although the postnatal onset of spindle waves in humans suggests that this is a possibility.

In the present study, we investigated the postnatal development of spindle waves and the ability of block of $\mathrm{GABA}_{\mathrm{A}}$ receptors to induce a seizure-like oscillation in the ferret LGNd maintained in vitro. We demonstrate that spindle waves do not develop until after the period of segregation of retinogeniculate axons into specific laminae and sublaminae, and that the bicuculline-induced slowed oscillation develops even later, when PGN neurons develop the capability to generate prolonged and high frequency burst discharges.

\section{Materials and Methods}

For the preparation of slices, male or female ferrets, from $10 \mathrm{~d}$ (P10) to $53 \mathrm{~d}$ (P53) after birth (P0 is the day of birth), were deeply anesthetized with sodium pentobarbital $(30-40 \mathrm{mg} / \mathrm{kg}$, i.p.) and killed by decapitation. The forebrain was rapidly removed and the hemispheres were separated with a midline incision. From four to eight 400 - $\mu$-thick slices were formed using a vibratome (Ted Pella, Inc.) in the sagittal plane from the two LGNds obtained from each animal. A modification of the technique developed by Aghajanian and Rasmussen (1989) was used to increase tissue viability. During preparation of siices, the tissue was placed in a cold solution (approximately $5^{\circ} \mathrm{C}$ ) in which $\mathrm{NaCl}$ was replaced with sucrose while maintaining an osmolarity of $307 \mathrm{mOsm}$. After formation on the vibratome, slices were placed in an interface style recording chamber (Fine Sciences Tools) and allowed at least 2 hr to recover. The bathing medium contained (in $\mathrm{mM}$ ) NaCl, 126; KCl, 2.5; $\mathrm{MgSO}_{4}, 1.2 ; \mathrm{NaH}_{2} \mathrm{PO}_{4}, 1.25 ; \mathrm{CaCl}_{2}, 2 ; \mathrm{NaHCO}_{3}, 26 ;$ dextrose, 10; and was aerated with $95 \% \mathrm{O}_{2}, 5 \% \mathrm{CO}_{2}$ to a final pH of 7.4. For the first 20 min that the geniculate slices were in the recording chamber, the bathing medium contained an equal mixture of the normal $\mathrm{NaCl}$ and the sucrose-substituted solutions. Temperature was maintained at $34-35^{\circ} \mathrm{C}$. Following $2 \mathrm{hr}$ of recovery, extracellular multiple unit recordings were performed from multiple locations in each slice to determine the prevalence of spontaneous spindling activity.

For extracellular recordings in vivo, 14-60-d-old male or female ferrets were anesthetized with sodium pentobarbital $(30 \mathrm{mg} / \mathrm{kg}$, i.p.) and mounted in a Kopf stereotaxic device. Rectal temperature was maintained at $36-37^{\circ} \mathrm{C}$ through circulating water thermal blankets, and the animal's electrocardiogram was monitored. The LGNd was located both through stereotaxic coordinates ( 3 week old, $6-7 \mathrm{~mm}$ anterior to lambda, 4-5 mm lateral to midline, 6-9 mm ventral to surface of cortex; 3 month old, $11.5-13 \mathrm{~mm}$ anterior, 5-6 $\mathrm{mm}$ lateral, $7.5-9 \mathrm{~mm}$ ventral) and by testing the response to flashes of light to the contra- or ipsilateral retina generated by an ophthalmoscope. Although spindle waves could be recorded in the barbiturate-anesthetized ferret LGNd, these spindle waves were enhanced by block of retinal activity. Therefore, tetrodotoxin $(100 \mu \mathrm{M})$ was injected into each eye with a 30 gauge needle to block spontaneous retinal activity after the extracellular recording microelectrode was placed in the LGNd. Although extracellular recordings from LGNd relay and PGN neurons can be readily distinguished in the adult animal, this was not attempted in the present recordings from immature animals.

Intracellular recording electrodes were formed on a Sutter Instruments P-80 micropipette puller from medium-walled glass (WPI, 1B100F), and beveled on a Sutter Instruments beveler. Micropipettes were filled with either $4 \mathrm{M} \mathrm{K}$-acetate or, in some cases, with $1.5 \mathrm{M}$ $\mathrm{K}$-acetate and $2 \%$ biocytin for intracellular labeling of recorded neurons. Biocytin-filled neurons were visualized through standard avidin-biotinhorseradish peroxidase reaction visualized with diaminobenzidine (Horikawa and Armstrong, 1988). Electrical stimulation of afferent fibers was achieved through the placement of a concentric stimulating electrode in the structure to be stimulated and delivering 1-5 stimuli ( 100 $\mu s e c$ duration; $10-500 \mu \mathrm{A}$ amplitude; $100-200 \mathrm{~Hz}$ frequency). The LGNd was identifiable at all ages in the slice preparation. The PGN was identified as a band of neurons present anterior to the LGNd and within the fibers of the optic radiation. These neurons also exhibited characteristic EPSPs and EPSP barrages upon stimulation of the optic radiation.

\section{Results}

Extracellular multiple unit recordings from the LGNd and surrounding thalamic regions in barbiturate-anesthetized ferrets ( $n$ $=21$ ), and after block of retinal activity with intraocular injection of tetrodotoxin $(100 \mu \mathrm{M})$, revealed that spindle waves are absent at ages less than approximately 3 weeks ( $n=5$ animals, 2-3 weeks old). Around 3 weeks of age, extracellular recordings occasionally revealed spontaneous rhythmic activity at frequencies of about 2-6 Hz, although clear spindle waves were not yet present (Fig. 1A). Over the next 3 weeks, spindle waves became more prevalent, more regular in structure, and possessed a higher density of neurons firing during each spindle wave $(n=6$ animals, 4-6 weeks old). At the age of 3 months, spindle waves in the LGNd were robust and recurred once every 3-7 sec, with intraspindle frequencies of approximately $6-9 \mathrm{~Hz}$ (Fig. $1 B ; n=$ 10 animals).

\section{Geniculate slices at postnatal ages $P 10-18$}

In similarity with in vivo recordings, extracellular multiple unit and intracellular recordings in sagittal slices of the ferret LGNd failed to reveal either spontaneous or evoked (optic radiation stimulation) spindle waves at ages between P12 and P18 $(n=$ 


\section{Development of Spindle Waves In Vivo}

\section{A. 3 weeks old}
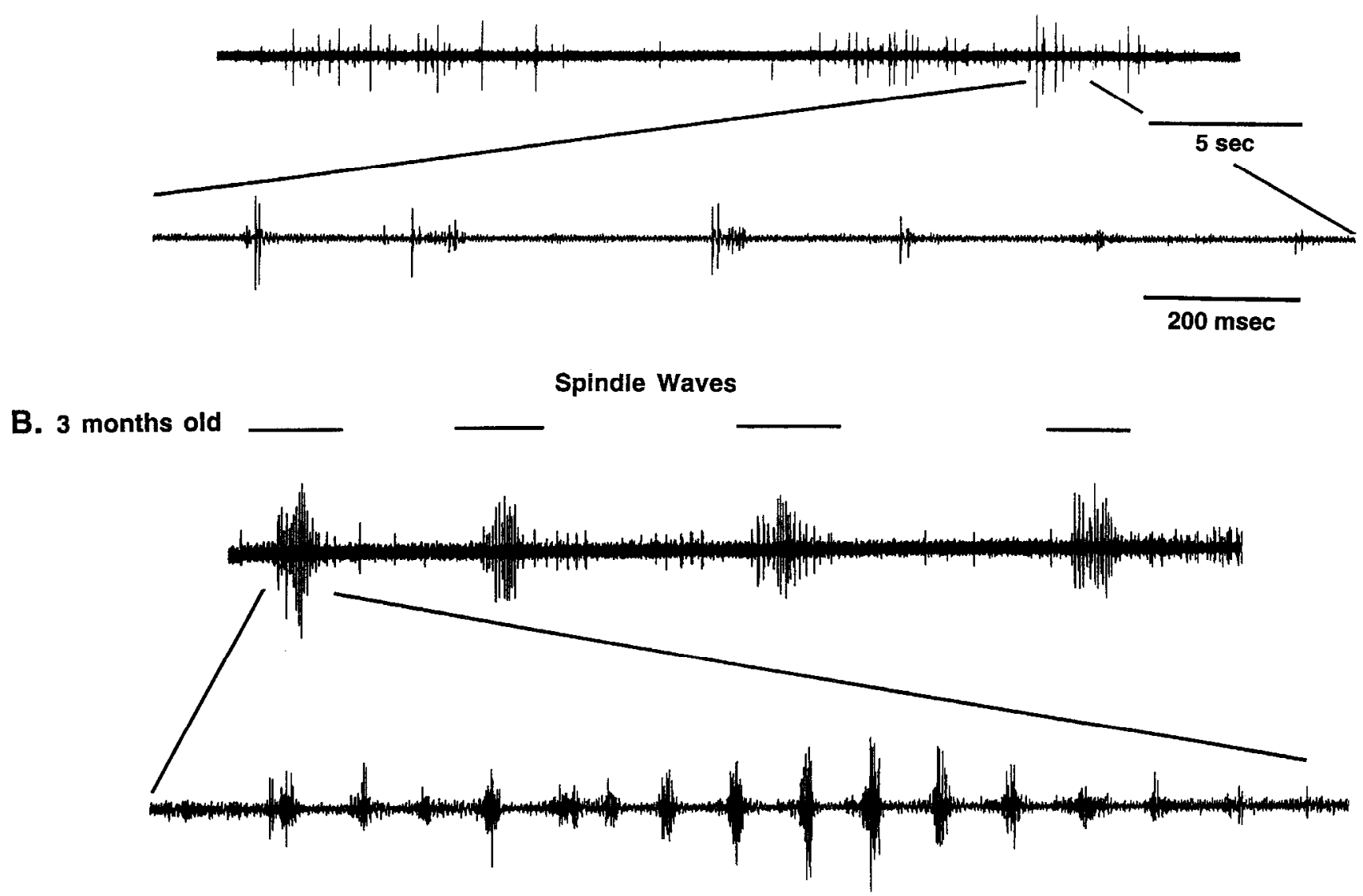

Figure 1. Development of spindle wave oscillations in the ferret thalamus in barbiturate-anesthetized ferrets. Extracellular multiple unit recordings from the ferret LGNd at 3 weeks $(A)$ and 3 months $(B)$ postnatal. $A$, At 3 weeks, spontaneous action potentials were present and this activity showed occasional periods of rhythmic activity (see expansion for detail), although clear spindle waves were not found. $B$, In contrast, extracellular multiple unit recordings from the LGNd at 3 months of age demonstrated clear spindle waves recurring about once every 5-7 sec. Each spindle wave was associated with synchronized rhythmic activity at about 6-9 $\mathrm{Hz}$ (see expansion for detail).

5 animals). Around the age of P18, electrical stimulation (five stimuli at $100 \mathrm{~Hz}$ ) of the optic radiation (OR) resulted in the activation of an IPSP in thalamocortical relay cells, occasionally followed by repetitive IPSPs, although no clear spindle waves were generated (Fig. 2, LGNd). These repetitive IPSPs presumably result from action potential activity in PGN neurons.

Extracellular recordings from the GABAergic PGN neurons at this age revealed that they responded to OR stimulation with short latency action potential discharge occasionally followed by irregular repetitive discharge (not shown). Intracellular recordings from PGN neurons at P18 revealed the occurrence of EPSPs in response to $\mathrm{OR}$ stimulation (Fig. 2, PGN), but no spindle waves. Interestingly, intracellular injection of hyperpolarizing current pulses at this age did not result in rebound low threshold $\mathrm{Ca}^{2+}$ spikes in PGN neurons, although similar pulses were followed by rebound $\mathrm{Ca}^{2+}$ spikes in thalamic relay neurons (Fig. 2 , lower traces).

Geniculate slices at postnatal ages $P 20-22$

Extracellular and intracellular recordings from slices prepared from animals aged P20-22 ( $n=3$ animals) revealed a lack of spontaneous spindle waves, although electrical stimulation (five stimuli, $100 \mathrm{~Hz}, 0.1 \mathrm{msec}$ duration; 50-500 $\mu \mathrm{A}$ ) resulted in abbreviated spindle waves characterized by 3-6 cycles of repetitive $6-9 \mathrm{~Hz}$ activity in the A-laminae and PGN (not shown).

\section{Geniculate slices at postnatal ages P26-30}

Between the ages of P26 and P30 ( $n=10$ animals), extracellular multiple and single unit recordings from the A-laminae of the LGNd or from the PGN revealed both spontaneous and optic radiation-evoked spindle waves, although these recordings also revealed that single cells in both the $\Lambda$-laminae and the PGN discharged only intermittently during the spindle waves, generating only one or two action potentials with each discharge ( $n$ $=5$ cells; not shown). Intracellular recordings from $L G N d$ relay neurons at the age of $\mathrm{P} 27$, for example, revealed the presence of spindle wave-associated repetitive IPSPs arriving in the frequency range of 6-9 $\mathrm{Hz}$ (Fig. 3A). These IPSPs were associated with occasional generation of rebound action potentials, although these action potentials typically occurred only one at a time and no bursts of two or more action potentials were seen (Fig. 3; expanded in $B$ for detail). Bath application of the GA- 


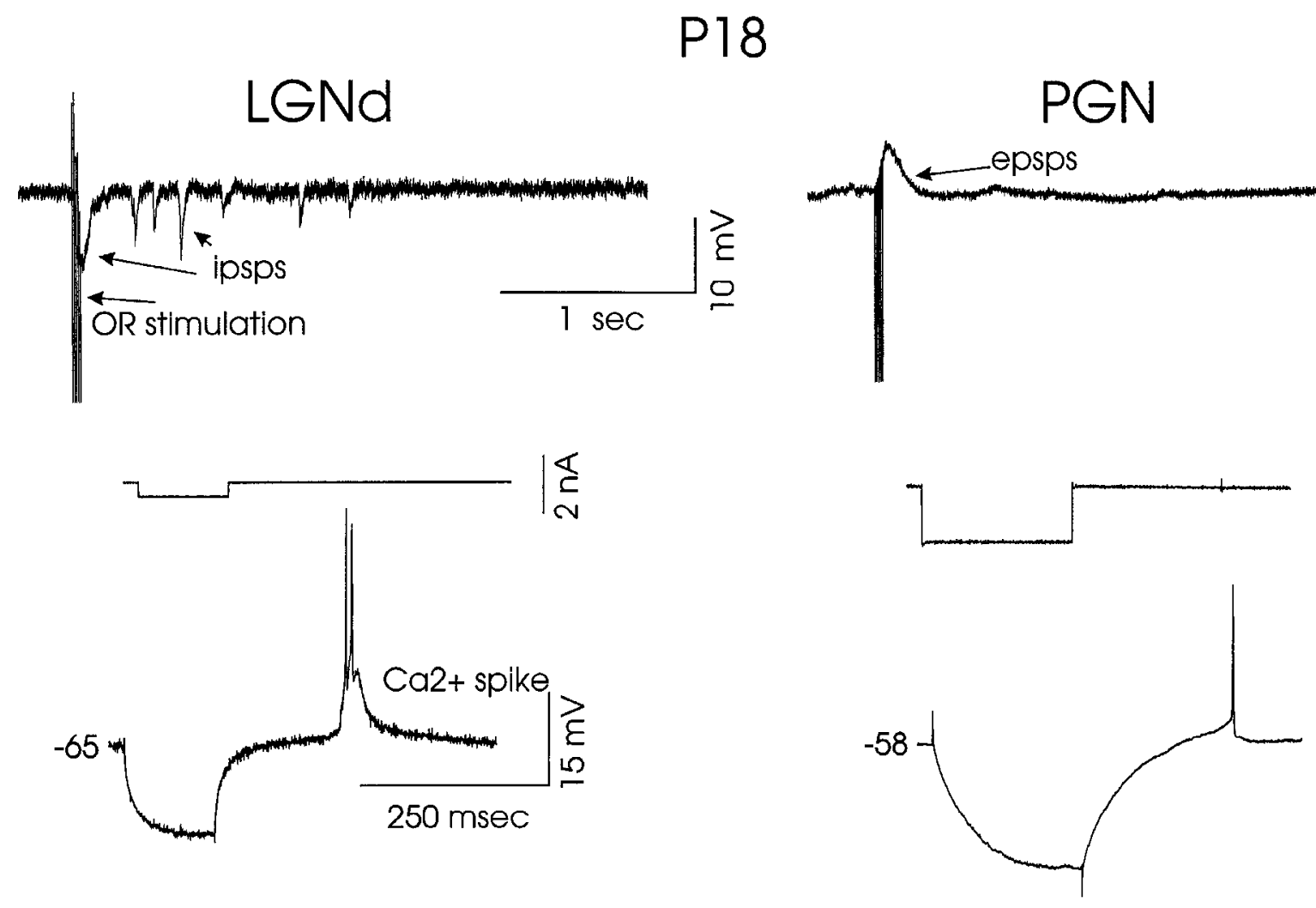

Figure 2. Response of LGNd relay cells and PGN GABAergic neurons to stimulation (five stimuli, $0.1 \mathrm{msec}$ duration, $200 \mathrm{~Hz}$ ) of optic radiation at P18. At this age, spindle waves are not evoked, although a somewhat disorganized barrage of repetitive IPSPs was sometimes seen in thalamocortical relay cells.

$\mathrm{BA}_{\mathrm{A}}$ receptor antagonist bicuculline methiodide $(20 \mu \mathrm{M})$ at this age resulted in a complete block of spindle wave generation (Fig. $3 C$ ), and the initial IPSP was greatly reduced in amplitude and appeared to be slower in time to peak and longer in duration (compare Fig. $3 B, D$ ). Since the GABAergic neurons of the PGN are responsible for the generation of the IPSPs in LGNd relay cells during normal spindle wave generation, and since the generation of the bicuculline-induced slow oscillation requires prolonged and high frequency burst discharges in PGN cells (Bal et al., 1995a,b), these results suggest that action potential activity in perigeniculate neurons may be rather limited at this age.

Extracellular multiple unit and single unit recordings from the PGN at P28 revealed that spindle waves were associated with rather weak and intermittent activity in these cells (e.g., Fig. 4A, PGN extracellular). Simultaneous intracellular recording from a PGN neuron and extracellular multiple unit recording in the nearby $(<100 \mu \mathrm{m})$ region of the PGN revealed that spindle waves were associated with the occurrence of barrages of EPSPS with interbarrage frequencies of approximately $6-9 \mathrm{~Hz}$ (Fig. $4 A$, PGN intracellular). At resting membrane potential $(-68 \mathrm{mV}$ in this neuron) these EPSP barrages occasionally activated single action potentials in this PGN neuron (Fig. 4A,B). Hyperpolarization of the PGN neuron with intracellular injection of current to a membrane potential of $-77 \mathrm{mV}$ enhanced the amplitude of the EPSPs arriving during the generation of the spindle wave, although these events still generated only single action potentials in the PGN neuron; no low threshold $\mathrm{Ca}^{2+}$ spike-mediated bursts of two or more action potentials were found (Fig. 4C,D).

The presence of EPSPs in PGN neurons during the generation of spindle waves at P28 suggests that these cells are innervated by thalamocortical relay neurons located in the A-laminae. Indeed, local application of glutamate in either lamina A or Al resulted in barrages of EPSPs in this PGN neuron (Fig. $4 E, F$ ) which could activate action potentials, in similarity with the generation of spindle waves.

We have previously found that spindle waves in adult PGN cells are often associated with the arrival of both EPSPs and IPSPs, with the IPSPs presumably arising from activity in neighboring PGN neurons (Bal et al., 1995b). Similarly, we also occasionally observed at P26-30 inhibitory postsynaptic potentials in PGN neurons during the generation of spindle waves (Fig. 5). In the PGN cell of Figure 5, for example, a spindle wave was activated through stimulation of the optic radiation. Extracellular multiple unit recording in the PGN revealed the occurrence of a spindle wave, although it was rather weak and disorganized in comparison with those found in tissue from older animals. The intracellular recording from a PGN cell revealed the occurrence of IPSPs in this neuron during the generation of the spindle wave. These IPSPs exhibited a relatively rapid rate of onset (15$25 \mathrm{msec}$ time to peak) and a duration of $70-120 \mathrm{msec}$ (Fig. 5). In addition to IPSPs, clear EPSPs were also seen, and these were occasionally associated with activation of single action potentials (Fig. 5; see inset). Activation of a spindle wave at a more hyperpolarized membrane potential resulted in a block or reversal of these inhibitory postsynaptic potentials (Fig. 5, $-91 \mathrm{mV}$ ). These results suggest that by the age of P26-30, PGN neurons inhibit one another through the activation of short duration, fast inhibitory postsynaptic potentials (see Bal et al., 1995b).

Bath application of the $\mathrm{GABA}_{\mathrm{A}}$ receptor antagonist bicuculline methiodide $(20 \mu \mathrm{M})$ at the ages of $\mathrm{P} 26-30$ resulted in an 


\section{P27 - LGNd}
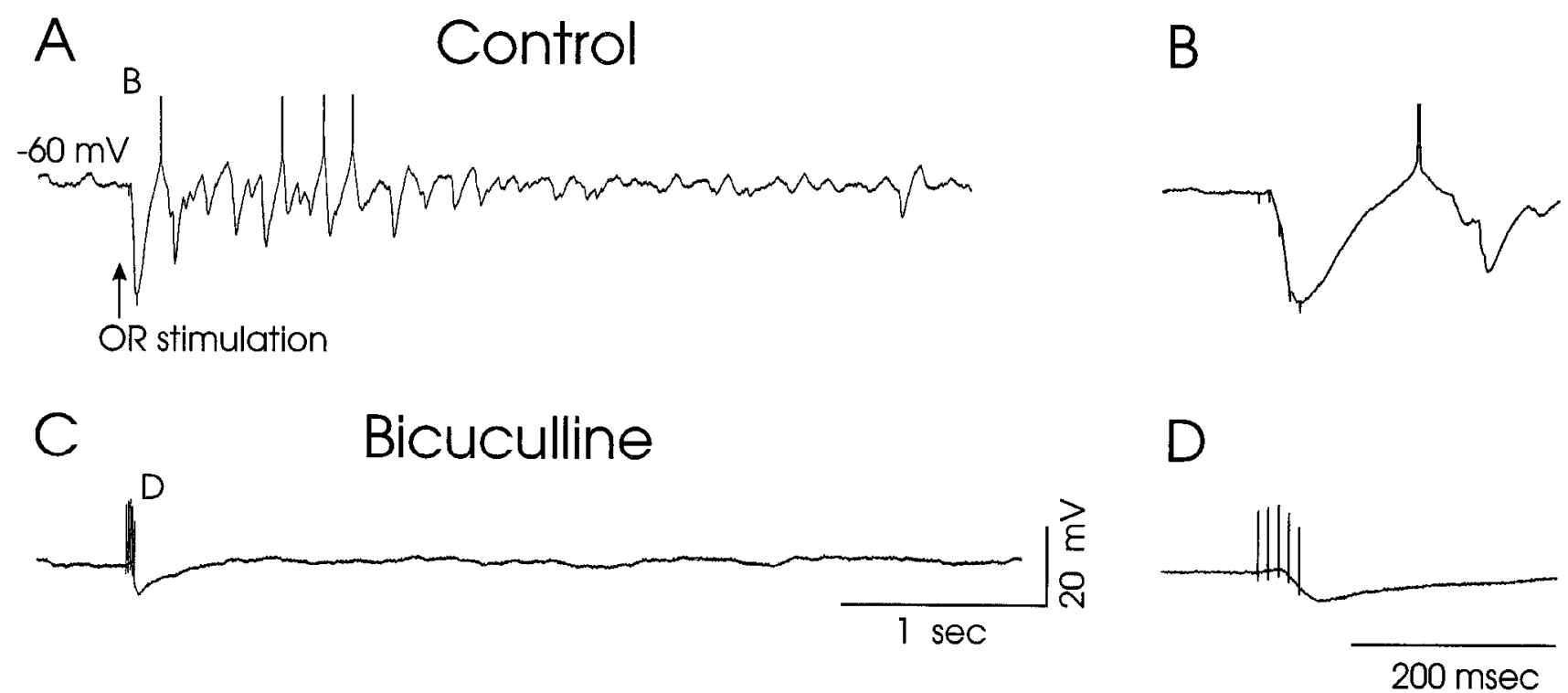

Figure 3. Activation of optic radiation results in the generation of a spindle wave at P27 $(A)$, as revealed by the occurrence of rhythmic IPSPs in this thalamocortical relay cell. At this age, repetitive IPSPs are associated with only weak rebound responses in relay cells, consisting of one or two action potentials (see expansion in B). Bath application of bicuculline ( $20 \mu \mathrm{M}$ ) abolishes the spindle wave and leaves only the initial IPSP, which exhibits a slower rate of rise and a more prolonged duration.

abolition of spindle wave generation in the PGN (not shown). In the presence of bicuculline, activation of optic radiation fibers resulted in discharge of PGN neurons during the stimulation, followed by a second, smaller discharge at a latency of approximately $300 \mathrm{msec}$ (Fig. 6A). Intracellular recordings from PGN neurons at this age revealed the presence of EPSPS during the stimulation of the optic radiation, followed by a $200-300 \mathrm{msec}$ duration hyperpolarization or afterhyperpolarization (Fig. 6, -58 $\mathrm{mV}, \mathrm{AHP}$ ). This afterhyperpolarization was often followed by a rebound low threshold $\mathrm{Ca}^{2+}$ spike and a burst of two action potentials (Fig. 6A,B). Hyperpolarization of the PGN neuron revealed underlying EPSPs during stimulation of the optic radiation, as well as a small barrage of EPSPs arriving at a latency of approximately $300 \mathrm{msec}$ indicating that thalamic relay neurons may be firing at this latency (Fig. 6A).

\section{Geniculate slices at postnatal ages P33-39}

Intracellular and extracellular recordings from the A-laminae and PGN at ages P33-39 ( $n=7$ animals) revealed robust spontaneous and evoked spindle waves in both regions. Bath application of bicuculline $(20 \mu \mathrm{M})$ resulted in an abolition of spontaneous spindle wave generation. Electrical stimulation of the optic radiation in the presence of bicuculline evoked only 2-3 cycles of a synchronized slow oscillation of approximately 2-4 $\mathrm{Hz}$ (not shown; see below).

\section{Geniculate slices at postnatal ages P4I-53}

Intracellular and extracellular recordings from LGNd relay neurons and PGN cells at ages $\mathrm{P} 41-53$ ( $n=7$ animals) revealed robust spontaneous or optic radiation stimulation-evoked spindle waves (Figs. 7, 8). In thalamic relay cells, these spindle waves were associated with the arrival of repetitive IPSPs at frequencies of $6-9 \mathrm{~Hz}$, and the occurrence of rebound low threshold $\mathrm{Ca}^{2+}$ spikes that were synchronized with the local ac- tivity in the A-laminae (Fig. $7 A, B$ ). As we have reported previously (Bal et al., 1995a,b), these rebound $\mathrm{Ca}^{2+}$ spikes occurred on a rather regular basis at a rate of about $2-4 \mathrm{~Hz}$, in keeping with the intrinsic propensity of thalamic relay neurons to discharge at this frequency (McCormick and Pape, 1990) (Fig. 7A). At P41-53, bath application of bicuculline methiodide $(20 \mu \mathrm{M})$ was typically associated with the conversion of normal spindle waves into a marked slow oscillation with intraoscillatory frequencies of approximately $2-4 \mathrm{~Hz}$ (Fig. 7C). These bicucullineinduced oscillations were associated with marked burst firing in thalamic relay cells such that these neurons discharged with most every cycle, in synchrony with activity in the neighboring portion of the A-lamina (Fig. 7C,D). These effects were reversible upon washout of bicuculline (Fig. $7 E, F$ ).

Intracellular recordings from $P G N$ neurons in this age range revealed that during the generation of normal spindle waves, these cells receive repetitive barrages of EPSPs and generate robust high frequency $(225-425 \mathrm{~Hz})$ bursts of 5-12 action potentials riding on top of a presumed low threshold $\mathrm{Ca}^{2+}$ spike (Fig. 8A,C). Simultaneous recordings from lamina $\mathrm{A}$ in the neighboring region of the LGNd revealed that each burst of activity in presumed relay cclls was associated with the arrival of EPSPs in the PGN neuron, as we have reported previously (Bal et al., 1995b). During each spindle wave, PGN neurons slowly hyperpolarized, and following the end of the spindle wave, this hyperpolarization persisted as an afterhyperpolarization (Fig. $8 A)$.

Bath application of bicuculline methiodide $(20 \mu \mathrm{M})$ resulted in a conversion of these normal spindle waves into the $2-4 \mathrm{~Hz}$ slowed oscillation. During the generation of this bicuculline-induced slow oscillation, PGN neurons generated high frequency (up to $650 \mathrm{~Hz}$ ) bursts of up to 50 action potentials (Fig. $8 B, D$ ). Each burst of action potentials appeared to be generated through the activation of a low threshold $\mathrm{Ca}^{2+}$ spike that was triggered 

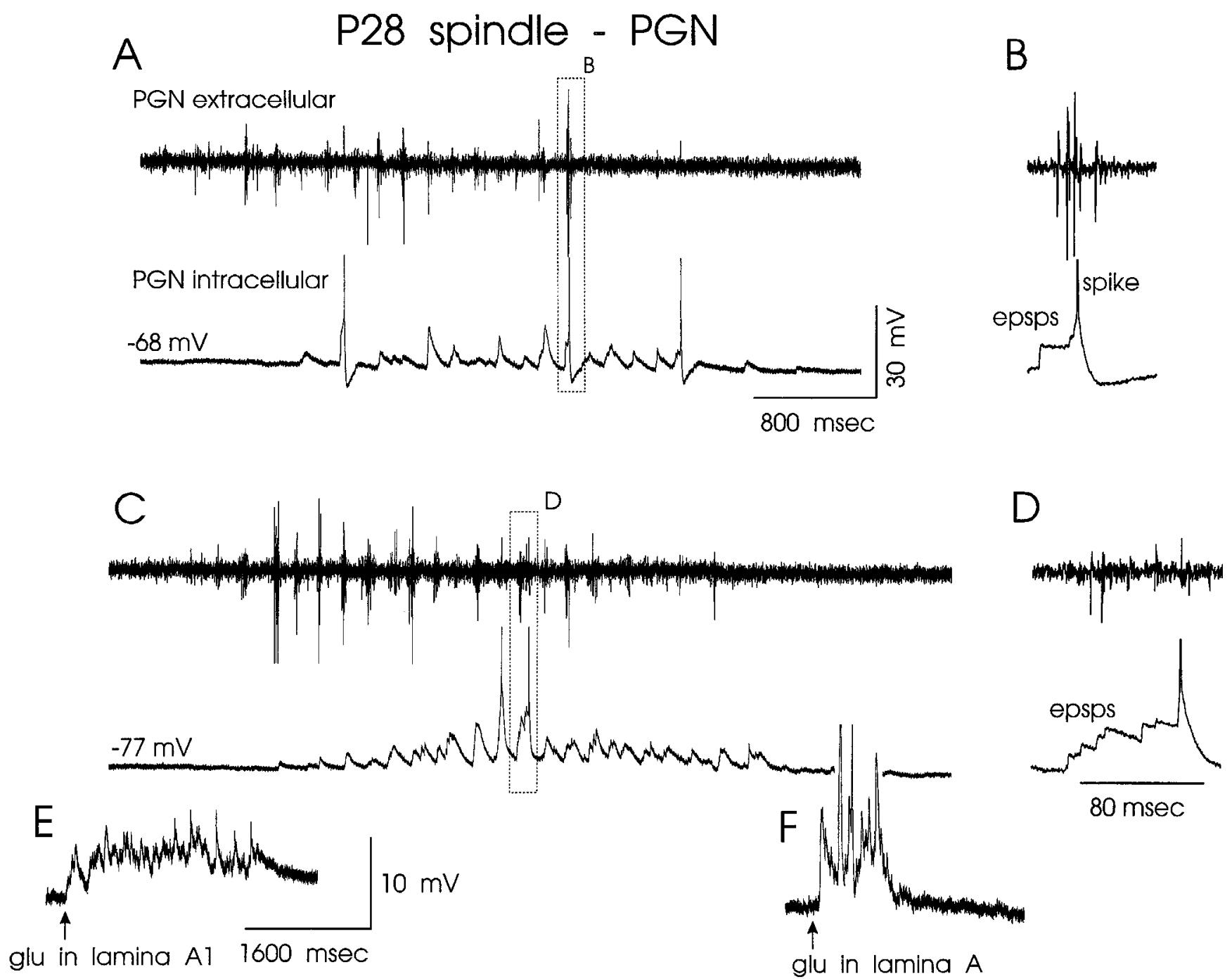

Figure 4. Simultaneous extracellular and intracellular recording of spindle wave generation in PGN neurons at P28. Spindle waves at this age are associated with relatively weak rhythmic activity in the extracellular multiple unit recordings in the PGN ( $A, C$; PGN extracellular) as well as in the simultaneous intracellular PGN recording ( $A$; PGN intracellular). Each burst of activity is associated with the arrival of barrages of EPSPs and the activation of typically one, and sometimes two, action potentials (expanded in $B$ for detail). $C$, Additional spindle wave recorded while the PGN neuron was hyperpolarized to a membrane potential of $77 \mathrm{mV}$. At this membrane potential, the barrages of LPSPs associated with the spindle wave are more evident, although they still activate only one action potential (expanded in $D$ for detail). Stimulation of thalamic relay cells in either lamina A1 $(E)$ or A $(F)$ with local "puffer" application of glutamate (1 mM in micropipette) resulted in pronounced barrages of EPSPs and occasional action potentials in this PGN neuron.

by barrages of EPSPs. As during spindle wave generation, these EPSPs were synchronous with the occurrence of action potential activity in the neighboring region of the LGNd (Fig. 8B,D); PGN neurons progressively hyperpolarized during the generation of these slow oscillations, and this hyperpolarization persisted as an afterhyperpolarization (Fig. 8B).

\section{Development of electrophysiological features of PGN neurons}

The present results, and those published previously (Bal et al., $1995 \mathrm{a}, \mathrm{b})$, suggest that the ability of PGN neurons to generate robust low threshold $\mathrm{Ca}^{2+}$ spikes is central to the generation of both spindle waves and the bicuculline-induced slow oscillation. Therefore, we examined the ability of PGN neurons to generate rebound low threshold $\mathrm{Ca}^{2+}$ spikes and high frequency action potential activity at different postnatal ages through the intracellular injection of hyperpolarizing and depolarizing current pulses. This feature was investigated at ages prior to onset of spindle wave generation (P15-18), at ages when spindle waves were robust but bicuculline-induced slow oscillations were absent (P26-30), and at ages when bicuculline application resulted in the generation of the slowed oscillation (P41-47).

Between the ages of P15 and P18, intracellular injection of hyperpolarizing current pulses in PGN neurons resulted in the generation of either no, or only single, rebound action potentials ( $n=4$ cells; Fig. $9 A$ ). Similarly, hyperpolarization of these cells to membrane potentials of $-90--110 \mathrm{mV}$ and intracellular injection of depolarizing current pulses did not result in the generation of low threshold $\mathrm{Ca}^{2+}$ spikes, but rather only single action potentials, once action potential threshold was reached by the depolarizing current pulse (not shown). Between the ages of P26 and P30, intracellular injection of hyperpolarizing current pulses resulted in the generation of rebound bursts of between 1 and 3 action potentials, mediated, presumably, through the activation of a low threshold $\mathrm{Ca}^{2+}$ spike $(n=10$ cells; Fig. 


\section{P27 IPSPs in PGN}

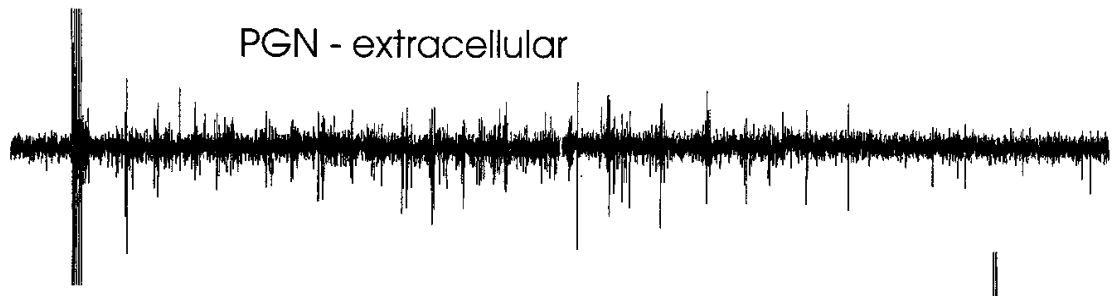
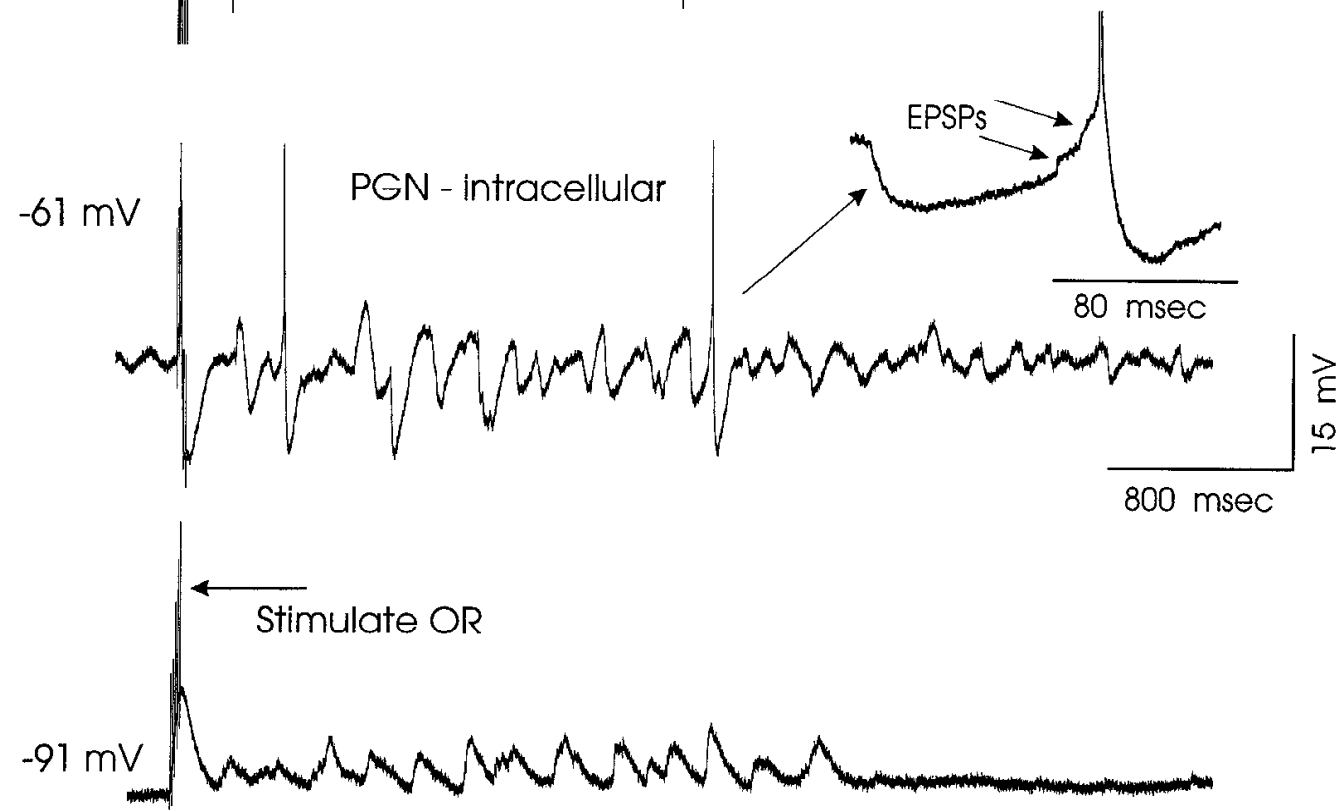

Figure 5. Inhibitory postsynaptic potentials are present in PGN neurons at P27. Simultaneous extracellular and intracellular recordings from PGN reveal the presence of spindle waves, although the extracellular recordings indicate that individual PGN neurons discharge only single action potentials during these oscillations. Intracellular recordings from a PGN neuron revealed the presence of both hyperpolarizing (inhibitory) and depolarizing PSPs at the membrane potential of -61 $\mathrm{mV}$. During this spindle wave, two action potentials were generated by this neuron and these were activated by EPSPs (see inset for detail). Hyperpolarization of this neuron to $-91 \mathrm{mV}$ with the intracellular injection of current revealed only depolarizing PSPs, suggesting that the IPSPs had been reversed or blocked.
$9 B, E)$. Between the ages of $\mathrm{P} 41$ and $\mathrm{P} 47$, intracellular injection of hyperpolarizing current pulses was followed by the generation of robust, rebound low threshold $\mathrm{Ca}^{2+}$ spikes ( $n-8$ cells; Fig. $9 C, F$ ) similar to those seen in the adult (Bal and McCormick, 1993; Bal et al., 1995a,b). In addition, at these older ages, the burst of action potentials in single PGN neurons were associated, at a latency of about $150 \mathrm{msec}$, with barrages of EPSPs (Fig. $9 F$, feedback EPSPs), which are generated by rebound burst firing in thalamocortical relay cells induced by the burst discharge of the recorded PGN cell (Bal et al., 1995a,b).

The intracellular injection of depolarizing current pulses into PGN neurons resulted in the generation of trains of action potentials (single spike firing) at all ages studied (P15-47; Fig. $10 A, B)$. However, there were a few notable differences that occurred during development. In particular, the duration of single action potentials in the PGN neurons decreased from the ages of P15 to P47 (e.g., Fig. 10E). The average duration (at half maximal amplitude) of the first action potential in a train of spikes at ages P15-18 was $0.99 \mathrm{msec}( \pm 0.16 ; n=4)$, at P2732 was $0.60 \mathrm{msec}( \pm 0.09 ; n=6)$, and at $\mathrm{P} 41-47$ the average duration had decreased to $0.36 \mathrm{msec}( \pm 0.04 ; n=7 ; p<0.05)$. This decrease in duration was associated with an increase in the amplitude of the afterhyperpolarization that occurred immediately following the action potential (e.g., Fig. 10E). Indeed, examination of the first derivative with respect to time $(d V / d t)$ during the generation of action potentials revealed that the average peak rate of rise of the action potential at P15-18 for PGN neurons was $185 \mathrm{~V} / \mathrm{sec}( \pm 80 ; n=4)$, and the average rate of fall was $62 \mathrm{~V} / \mathrm{sec}( \pm 4)$. At ages $\mathrm{P} 27-32$ the average rate of rise was $672 \mathrm{~V} / \mathrm{sec}( \pm 122 ; n=6)$ and the average peak rate of fall was $122 \mathrm{~V} / \mathrm{sec}( \pm 34)$; while for neurons at P41 -47 , the average peak rate of rise was $613 \mathrm{~V} / \mathrm{sec}( \pm 105 ; n=7 ; p>0.05)$ and the average peak rate of fall was $232 \mathrm{~V} / \mathrm{sec}( \pm 42 ; p<0.05)$ (Fig. 10E).

Examination of $d V / d t$ during the generation of bursts of action potentials revealed a strong difference between PGN cells at the ages of $\mathrm{P} 27$ and $\mathrm{P} 42$ (Fig. 10C,D,F). At both ages, burst discharges were associated with a decrease in the peak rate of rise and fall of the action potential, particularly at the peak of the burst response. However, at the age of $\mathrm{P} 27$, the peak rate of action potential rise and fall dropped much more dramatically during the burst than in the older (P42) animals (Fig. 10F).

The frequency of action potentials generation during burst generation was lower at the less mature ages. Between the ages of P27 and P32, rebound action potential hursts occurred at peak frequencies of 200-300 Hz, while for neurons between P41 and $\mathrm{P} 47$, rebound bursts were characterized by frequencies in the range of $350-450 \mathrm{~Hz}$ (see Fig. $10 F$ ).

In addition to the longer duration of action potentials in the younger animals, we also noted that the frequency of action potential generation during tonic firing appeared to be limited at the younger ages. Indeed, examination of the frequency versus injected current $(f-I)$ relationships for the first interspike interval in PGN neurons at the ages of P27/P28 versus $\mathrm{P} 41-47$ revealed that at the younger ages, the PGN cells exhibit considerably lower slopes in their $f-I$ relations (Fig. 11). The average slope of the $f-I$ relation for cells at $\mathrm{P} 27 / \mathrm{P} 28$ was $91 \mathrm{~Hz} / \mathrm{nA}( \pm 32 ; n$ $=5$ ), while at the later ages of $\mathrm{P} 41-47$ the average slope was $432 \mathrm{~Hz} / \mathrm{nA}( \pm 191 ; n-6)$. Thus, with intraccllular injection of $0.9 \mathrm{nA}$, most cells at ages $\mathrm{P} 41-47$ generated frequencies well in excess of $250 \mathrm{~Hz}$, while cells at ages P27/P28 responded with frequencies limited to $50-150 \mathrm{~Hz}$. 


\section{P27 Bicuculline - PGN}

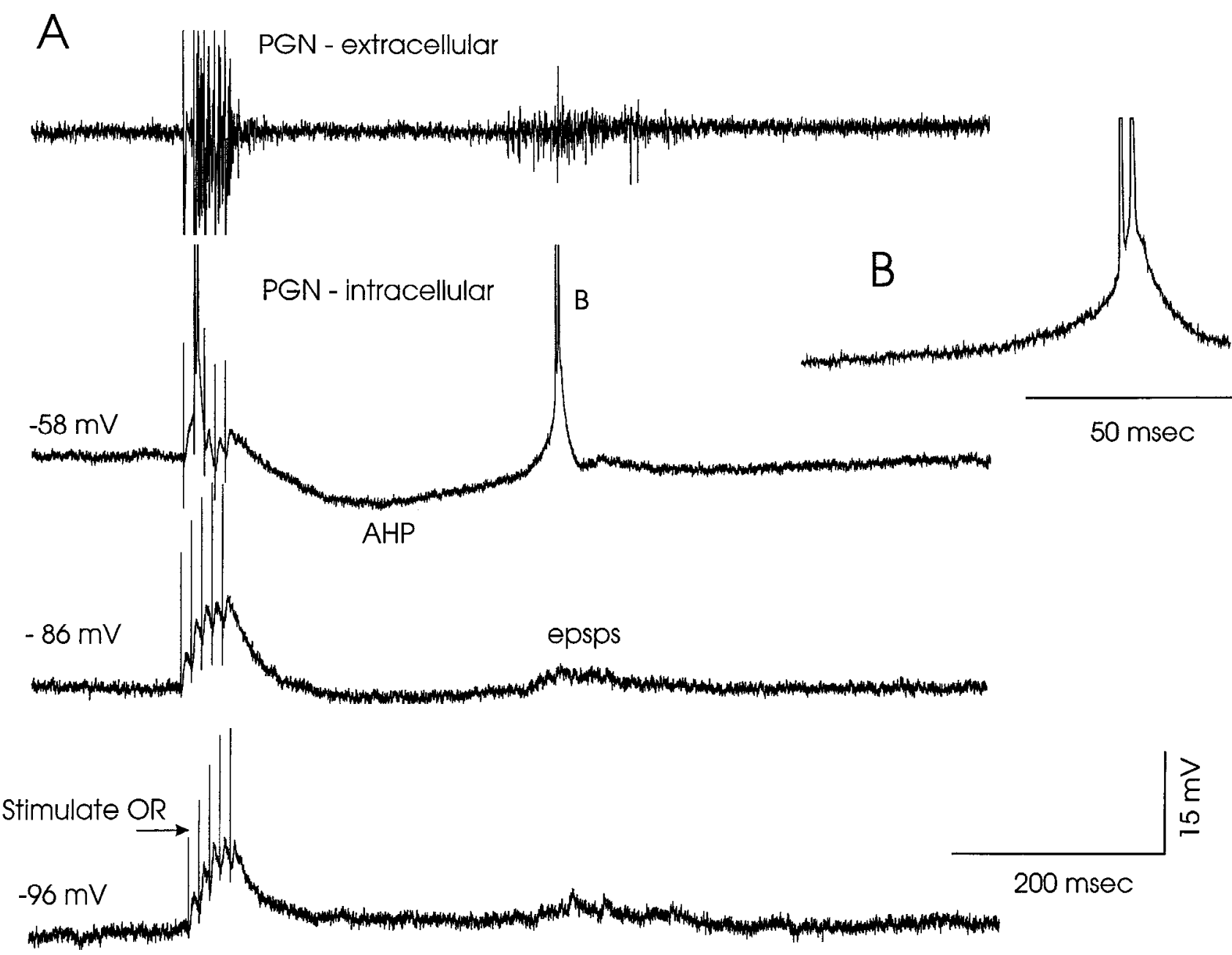

Figure 6. Block of $\mathrm{GABA}_{\mathrm{A}}$ receptors with the bath application of bicuculline methiodide $(20 \mu \mathrm{M})$ at $\mathrm{P} 27$ results in the block of spindle wave generation. Intracellular and extracellular recordings of PGN neurons in the presence of bicuculline reveal that stimulation of the optic radiation now results in the arrival of repetitive EPSPs, a burst of two action potentials, and a prolonged (approximately 300 msec) hyperpolarization that is followed by an additional burst of two action potentials (expanded in $B$ for detail). Hyperpolarization of the PGN neuron to -86 and $-96 \mathrm{mV}$ with intracellular injection of current reveals that these events are associated barrages of EPSPs.

\section{Discussion}

The present results demonstrate that in the ferret LGNd spontancous and cvokcd spindle waves first appear after approximately 3-4 weeks of postnatal age and become stronger and more prevalent during the following weeks. Weak spindle waves have been previously observed in the thalamus of the newborn cat, although they appear in the cortical EEG only after 2-3 d postnatal and become clear and consistent around postnatal days 8-9 (Domich et al., 1987). Considering that a newborn cat is approximately equivalent in developmental age to a 3-week-old ferret (Linden et al., 1981), these results suggest that the ferret and cat may exhibit a similar developmental time course of spindle wave development. In the human, spindle waves appear in the electroencephalogram (EEG) around the second month of life and increase in strength and regularity during the following several months and, perhaps, years (Metcalf, 1970; Fisch, 1991), although these spindle waves may appear earlier in the thalamus (e.g., Domich et al., 1987). There are likely to be several physiological and anatomical components of the ferret LGNd and PGN that must mature in the first few postnatal weeks before spindle waves can be readily generated. Spindle waves are generated as an interaction between thalamocortical relay neurons and the GABAergic neurons of the nucleus reticularis thalami/ perigeniculate nuclei (Steriade and Deschênes, 1984; Steriade et al., 1993; von Krosigk et al., 1993; Bal et al., 1995a,b). A burst of action potentials in PGN neurons induces a $\mathrm{GABA}_{\mathrm{A}}$ receptormediated IPSP in a large number of thalamocortical relay cells. The offset of this IPSP activates a low threshold $\mathrm{Ca}^{2}$ spike in a few of these relay neurons, and a subsequent burst of action potentials. This burst of action potentials in the relay cells then excites the GABAergic PGN neurons once again, and generates a burst of action potentials in many of these cells through activation of the low threshold $\mathrm{Ca}^{2+}$ current, thus starting the cycle again (von Krosigk et al., 1993; Bal et al., 1995a,b). With each cycle, more and more cells are recruited into the oscillation, as it grows (waxes) through the neural network (Kim et al., 1994; Bal et al., 1995a,b). The mechanisms by which the spindle wave stops (wanes) are not yet known.

We have previously reported that the ability of LGNd relay cells to generate low threshold $\mathrm{Ca}^{2+}$ spikes and bursts of action 

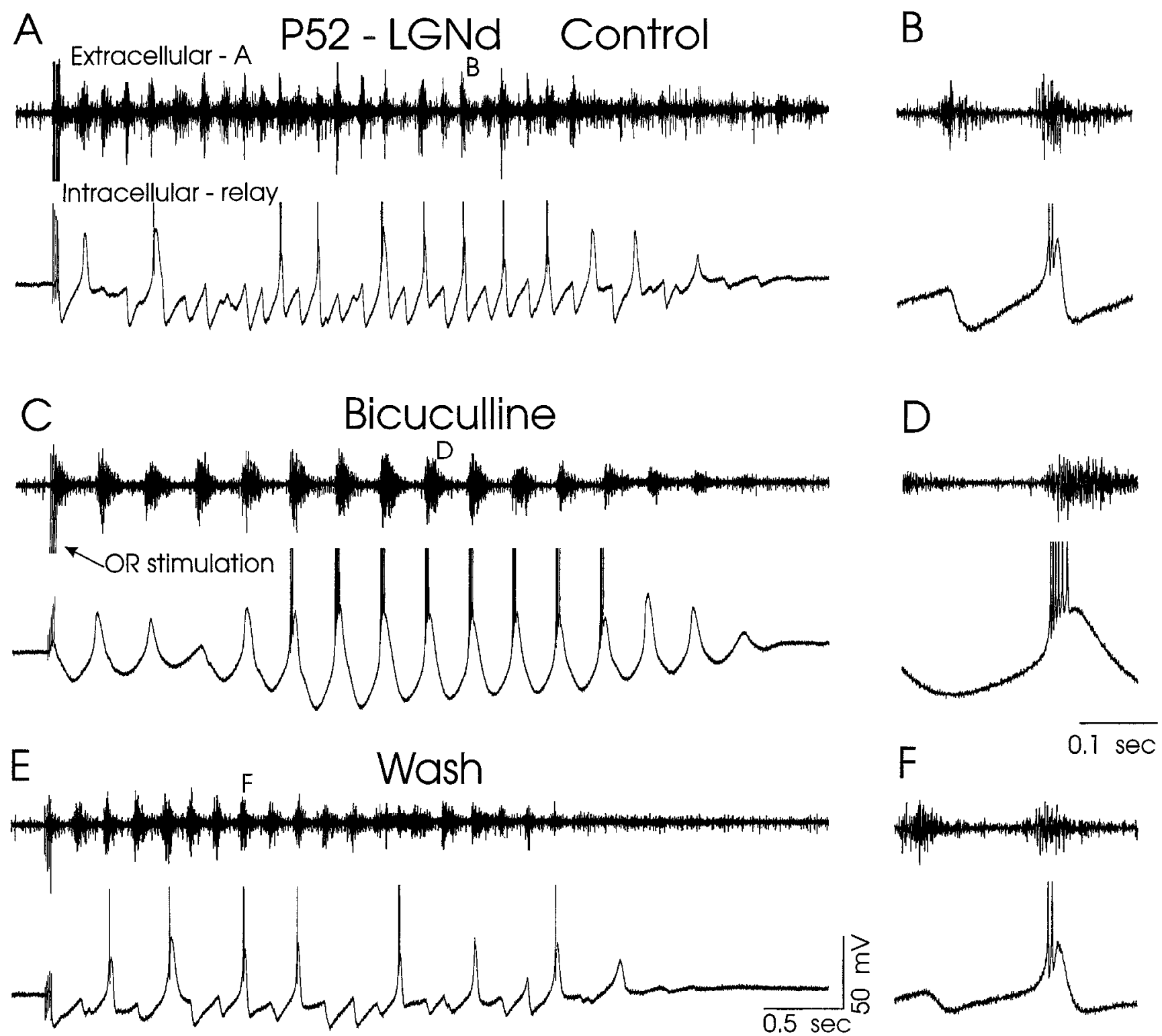

Figure 7. Block of $\mathrm{GABA}_{\mathrm{A}}$ receptors results in the transformation of spindle waves into the slowed oscillation at age P52. A, Extracellular and intracellular recordings from relay neurons in lamina A during the generation of a spindle wave evoked by electrical stimulation of the optic radiation. $B$, Expansion for detail of part of recording in $A$. $C$, Bath application of bicuculline (20 $\mu \mathrm{M})$ results in the generation of the slowed 2-3 $\mathrm{Hz}$ synchronized oscillation in relay neurons. $D$, Expansion of portion of $C$ for detail. $E$ and $F$, This effect of bicuculline is reversible.

potentials develops over the first 3-4 postnatal weeks in the ferret LGNd (Ramoa and McCormick, 1994a). Here, we demonstrate that PGN neurons also slowly develop the ability to generate high frequency burst discharges over the first 4-6 postnatal weeks, even though, like LGNd relay cells, PGN neurons can generate tonic trains of action potentials at all postnatal ages investigated (P15 to adult).

The postnatal development of burst discharges in PGN neurons is likely to be associated with two important factors. First, the amplitude of low threshold $\mathrm{Ca}^{2+}$ spikes activated through the intracellular injection of hyperpolarizing current pulses (or depolarizing current pulses during tonic hyperpolarization) increases markedly during the first postnatal month, suggesting that the underlying $\mathrm{T}$-current may be changing in either total available conductance or voltage dependence during this time period. An increase in the maximal available T-current, with no change in voltage dependence, during postnatal development of cat LGNd thalamocortical relay cells has been observed (Pirchio et al., 1990). Second, the ability of PGN neurons to generate high frequency trains of action potentials develops over the first several postnatal weeks in the ferret. Examination of the action potentials generated by PGN neurons reveals a decrease in duration and an increase in the maximal rate of rise, and particularly in the maximal rate of fall, of the action potential. These results are similar to those reported for rodent cortical pyramidal cells, where similar changes have been attributed to postnatal increases in the density of $\mathrm{Na}^{+}$and $\mathrm{K}^{+}$channels involved in action potential generation (McCormick and Prince, 1987; Huguenard et al., 1988). These changes in action potential generation are likely to contribute to the shallow frequency versus injected current properties of immature PGN cclls. As the density of $\mathrm{Na}^{+}$ and $\mathrm{K}^{+}$channels increases, the threshold for activation of $\mathrm{Na}^{+}$ spikes is likely to decrease (McCormick and Prince, 1987; Ramoa and McCormick, 1994a) and the ability of the cell to gen- 

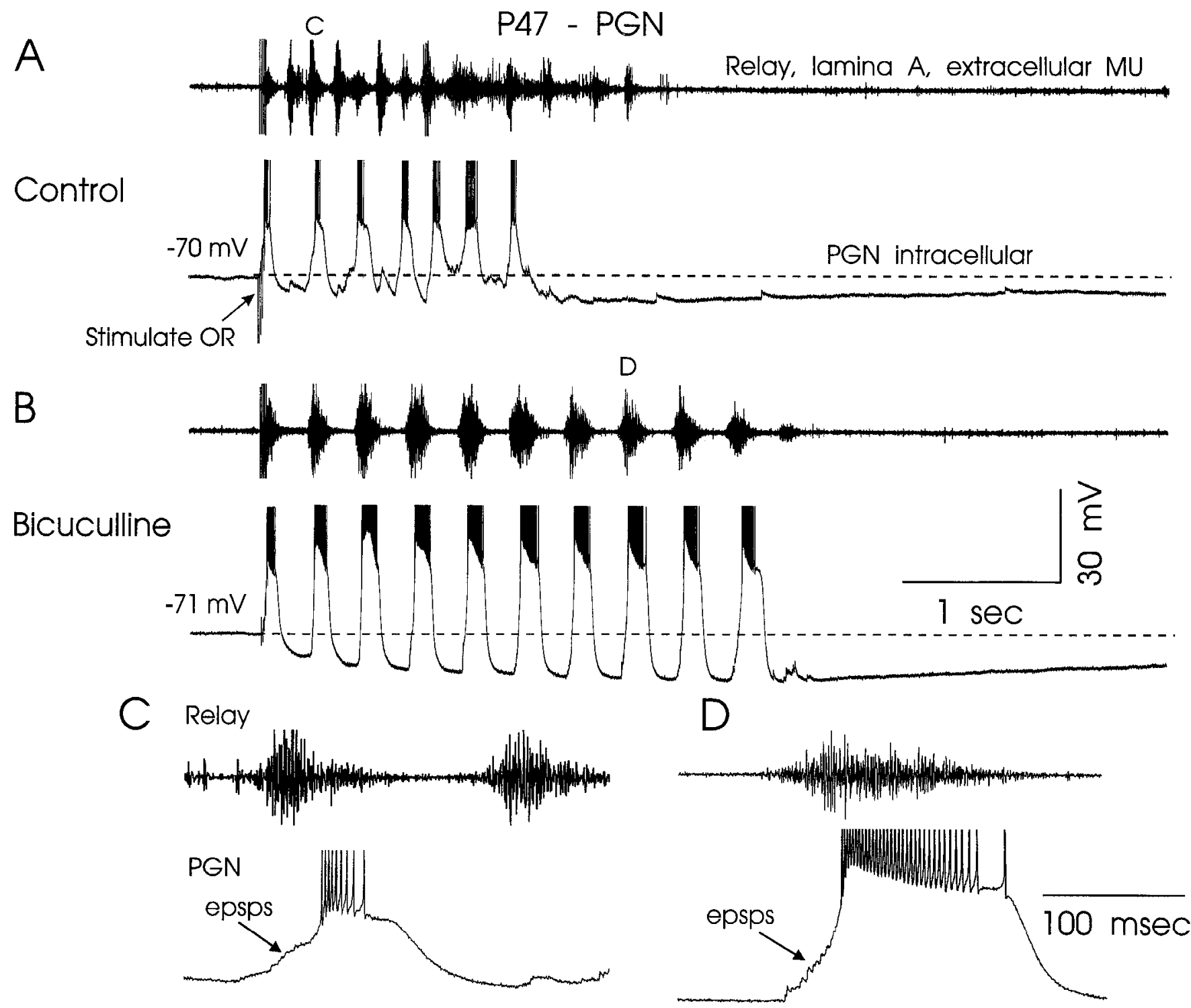

Figure 8. Intracellular recording from a perigeniculate cell during the transition from normal spindle wave generation to the slowed oscillation. $A$, Al age P47, evoked spindle waves are associated with barrages of EPSPs and burst firing in PGN neurons (see $C$ for detail). $B$, Bath application of bicuculline $(20 \mu \mathrm{M})$ results in the generation of the slowed oscillation, which is associated with pronounced bursts of action potentials in PGN neurons (see $D$ for detail).

erate action potentials at short (e.g., 2-3 msec) intervals increases, allowing the PGN neurons to generate the high frequency burst discharges associated with normal spindle wave generation in the adult (e.g., Steriade et al., 1986; Bal et al., 1995b). Presumably, increases in the number of action potentials generated per burst and the frequency of action potential generation during the burst will increase the amplitude and perhaps duration of the postsynaptic IPSPs in LGNd relay cells, thereby increasing the likelihood of generating a rebound low threshold $\mathrm{Ca}^{2+}$ spike, an event essential to spindle wave generation.

Absence seizures (spike-and-wave) in children are characterized by a delayed developmental onset, typically making their first clinical appearance at around 4-6 years of age (reviewed in Aicardi, 1994). Absence seizures can be exacerbated or precipitated by drowsiness, and in continuous recordings of the EEG, often occur most frequently during slow wave sleep (Kellaway, 1985). Animal models of spike-and-wave seizures indicate that there is a strong relationship between the cellular mech- anisms for generation of spindle waves and the cellular mechanisms for generation of spike-and-wave seizures (see review by Avoli et al., 1990; Buzsaki et al., 1990). In the feline generalized penicillin epilepsy model of spike-and-wave seizures, intramuscular injections of high doses of penicillin, which is a weak antagonist at $\mathrm{GABA}_{\mathrm{A}}$ receptors (reviewed in Macdonald and O1sen, 1994), or direct application of penicillin to the surface of the cortex results in a slow transformation of normal spindle waves into spike-and-wave seizures (Kostopoulos et al., 1981a,b; Avoli and Kostopoulos, 1982). This transformation is associated with a change in discharge pattern of cortical and thalamic neurons such that they both become locked into a sequence of strong action potential discharge during the spike and inhibition during the wave (Avoli and Gloor, 1982; Avoli and Kostopoulos, 1982). Recent elegant experiments have revealed that the spontaneous occurrence of spike-and-wave seizures in anesthetized cats is associated with a striking pattern of action potential generation during the spike and inhibition during the 


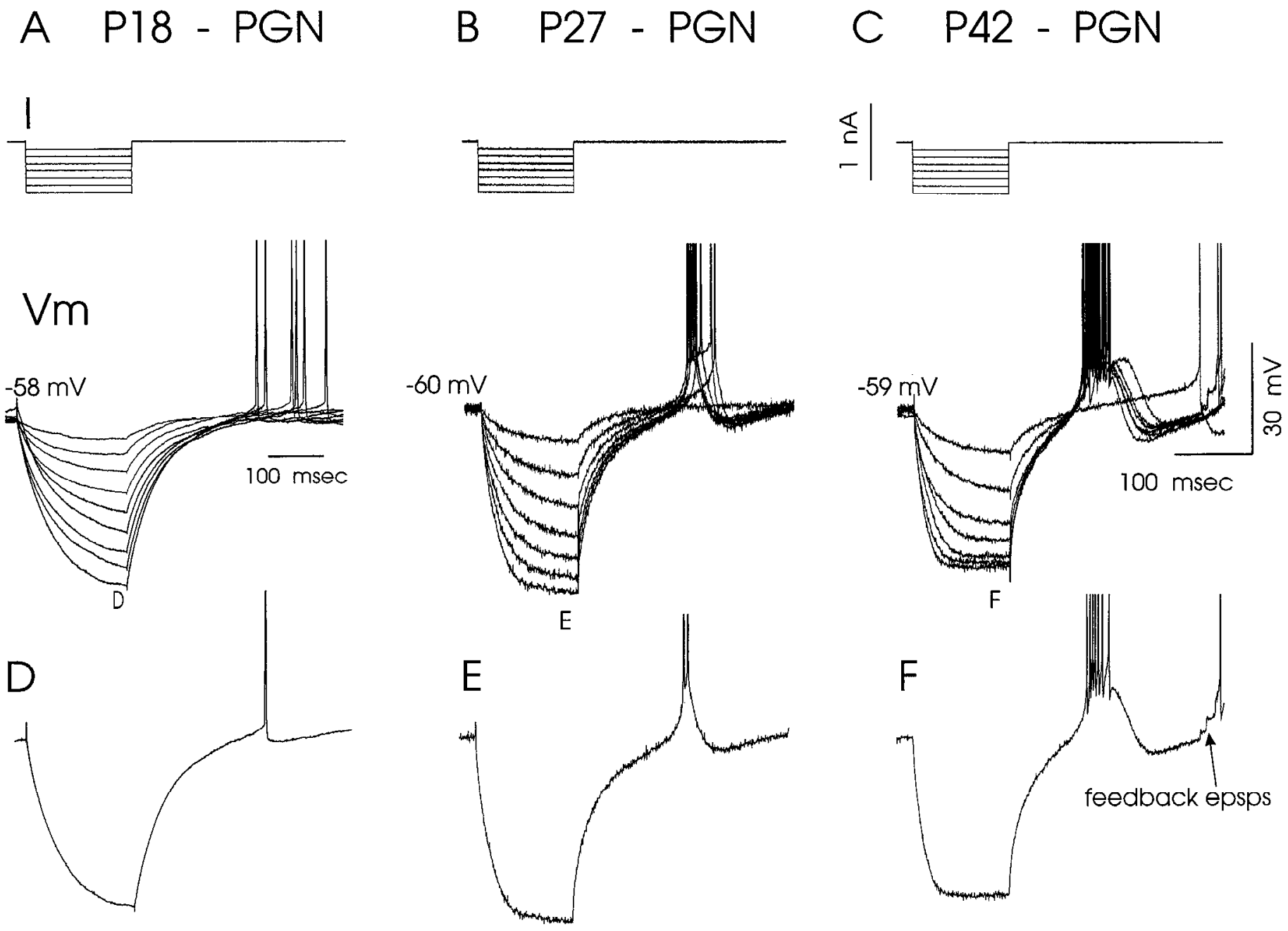

Figure 9. Response of PGN neurons to intracellular injection of hyperpolarizing current pulses at ages P18, P27, and P42. A, Intracellular injection of hyperpolarizing current pulses at P18 does not result in rebound low threshold $\mathrm{Ca}^{2+}$ spikes or burst responses, but rather the generation of only single action potentials. $B$, At P27, around the time of first appearance of spindle waves, rebound responses are limited to the generation of one or two action potentials. $C$, At P42, the adult pattern or rebound burst firing is seen in which PGN neurons generate robust rebound low threshold $\mathrm{Ca}^{2+}$ spikes and high frequency bursts of up to 10 action potentials. In addition, at this age, feedback follows the generation of burst firing in many PGN neurons $(F)$. Traces illustrated in $D-F$ are individual examples of responses to hyperpolarizing current pulses, as indicated in $A-C$.

wave in cells of the cerebral cortex, nucleus reticularis of the thalamus, and some thalamocortical relay neurons (Steriade and Amzica, 1994; Steriade et al., 1994; Steriade and Contreras, 1995). These findings suggest that spike-and-wave paroxysms are characterized by the occurrence of a perverse form of synchronized oscillation in thalamocorticothalamic loops, and therefore depend for their generation on the postnatal development of these circuits.

Recently, we demonstrated that block of GABA $\mathrm{A}_{\mathrm{A}}$ receptors in the ferret LGNd maintained in vitro results in a marked transformation of normal spindle waves into a slowed $(2-3 \mathrm{~Hz})$ oscillation in which all, or nearly all, thalamic relay and PGN neurons become locked into a burst-pause sequence of activity (von Krosigk et al., 1993; Bal et al., 1995a,b). We have proposed that this pattern of activity resembles that associated with the generation of spike-and-wave seizures and that it results from the pronounced burst discharges found in PGN neurons following disinhibition of these cells through block of $\mathrm{GABA}_{\mathrm{A}}$ receptors (Bal et al., 1995a,b). During normal spindle wave generation, PGN neurons receive barrages of EPSPs from burst firing in thalamocortical relay neurons. The amplitude of these barrag- es of EPSPs is regulated through nearly simultaneous barrages of $\mathrm{GABA}_{\mathrm{A}}$ receptor-mediated IPSPs, arriving presumably from the activity of neighboring PGN neurons (Bal et al., 1995a,b) through axon collaterals (Yen et al., 1985), or dendrodendritic synapses (Deschênes et al., 1985). Following the block of GA$\mathrm{BA}_{\mathrm{A}}$ receptors, the PGN neurons no longer inhibit one another and generate prolonged and high frequency bursts of action potentials during the generation of the slow oscillation (Bal et al., 1995b). We have proposed that these prolonged, high frequency bursts of action potentials are essential for the strong activation of $\mathrm{GABA}_{\mathrm{B}}$ receptors on thalamic relay neurons, which in turn is essential for the generation of the slowed, seizure-like oscillation (Bal et al., 1995b; see also Hosford et al., 1992).

In the present report, we found in ferret LGNd slices that block of $\mathrm{GABA}_{\mathrm{A}}$ receptors with bicuculline did not result in the generation of the slow oscillation between the ages of approximately P26 and P39, even though spindle waves were prevalent and inhibition between PGN neurons was present at these ages. These results suggest that at this age, relay-PGN circuits have not yet developed to a sufficient degree to allow for the generation of the bicuculline-induced paroxysmal activity. This de- 

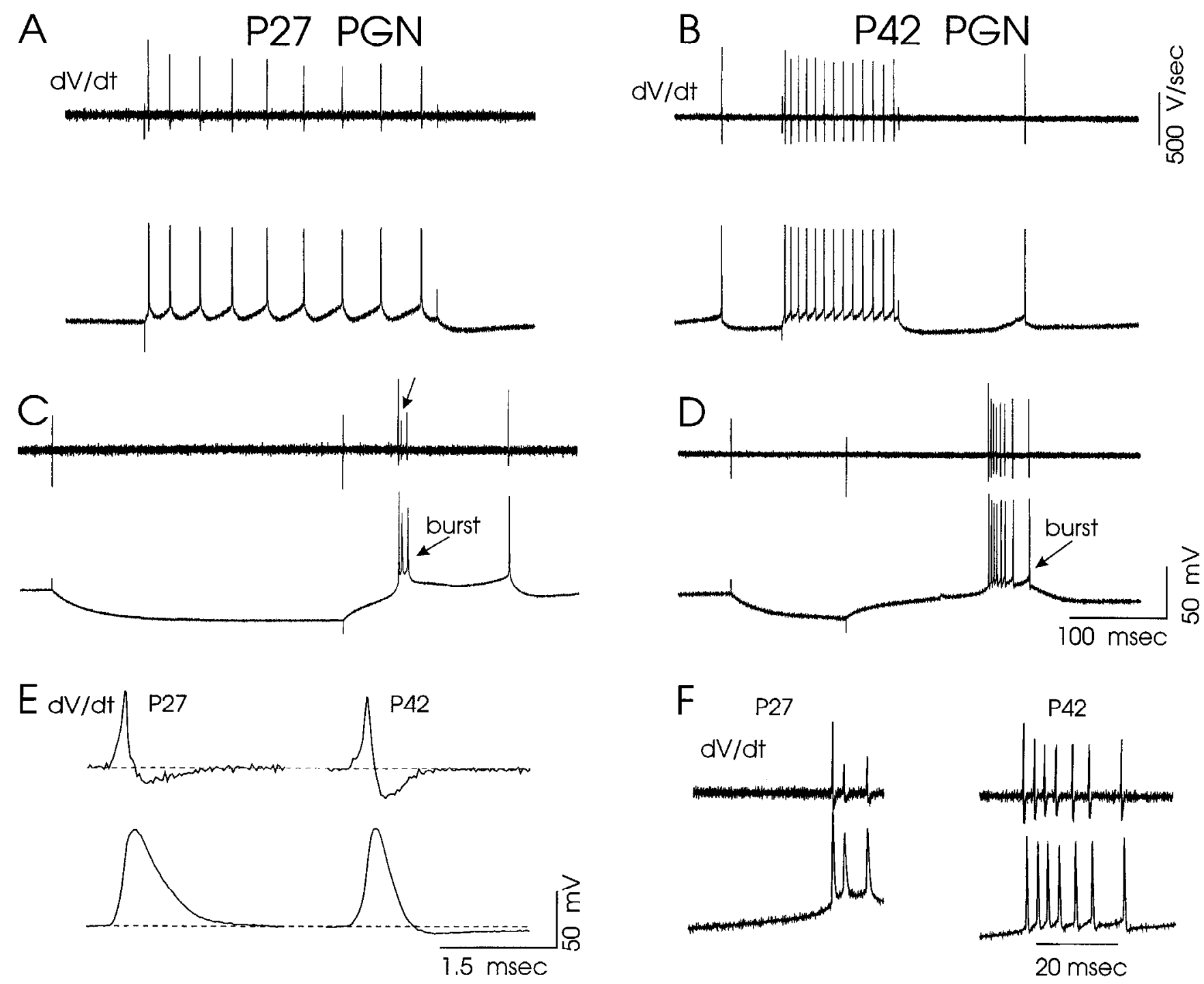

Figure 10. Electrophysiological properties of PGN neurons at ages when spindle waves first appear (P27) and when the bicuculline-induced oscillation first appears (P42). A, Intracellular injection of a depolarizing current pulse ( $0.5 \mathrm{nA})$ results in the generation of a low frequency train of action potentials. The first derivative $(d V / d t)$ of the voltage trace is illustrated as the top trace. $B$, Intracellular injection of a depolarizing current pulse $(0.5 \mathrm{nA})$ in a P42 PGN neuron results in a higher frequency of action potentials. $C$, Intracellular injection of a prolonged hyperpolarizing current pulse into a P27 PGN neuron results in a rebound burst of only three action potentials. $D$, Intracellular injection of a shorter duration hyperpolarizing current pulse results in the generation of a typical burst of action potentials in the P42 PGN cell. $E$, Comparison of $d V / d t$ and action potential waveform for the first action potentials in $A$ and $B$. At P27, PGN action potentials are longer in duration and have a less pronounced afterhyperpolarization and falling phase of the action potential. $F$, Similarly, during the burst response, the spike afterhyperpolarization in the P27 neurons is less pronounced and $d V / d t$ demonstrates a marked decrease during generation of the burst. These results suggest that at age P27, PGN neurons are still electrophysiologically immature, especially in their ability to generate high frequency bursts of action potentials.

layed development of the bicuculline-induced oscillation may be due to many underlying factors, both anatomical and physiological. In the present report, we found that these slow oscillations are largely absent until the electrophysiological properties of PGN neurons develop to a sufficient degree to allow these cells to generate high frequency and prolonged bursts of action potentials, a pattern of activity that we have previously proposed to be essential to the generation of this paroxysmal activity (Bal et al., 1995b). It is interesting to speculate that the delayed onset of absence seizures in children may be due, in part, to the delayed maturation of electrophysiological properties of GABAergic neurons in the nuclcus reticularis thalami and pcrigcniculate nuclei.

In addition to postnatal changes in electrophysiological properties, changes in intrathalamic anatomical connections also un- doubtedly contribute to the development of synchronized oscillations. Cytoarchitecturally, and in relation to retinogeniculate connections, the ferret LGNd obtains an adult-like appearance around P35-40 (Linden et al., 1981), even though the dorsal lateral geniculate and perigeniculate regions are identifiable at least as early as P1 in the ferret (Mitrofanis, 1994). To our knowledge, the postnatal development of axonal connections between perigeniculate and LGNd relay cells has not been thoroughly investigated. Our own unpublished results indicate that PGN neurons form inhibitory synaptic contacts with dorsolateral geniculate relay neurons at least as early as P10 (A. Ramoa and D. A. McCormick, unpublished observations), although the possibility that these inhibitory synapses may function differently than those in the adult, as has been demonstrated in the hippocampus (reviewed in Cherubini et al., 1991), has not yet been 


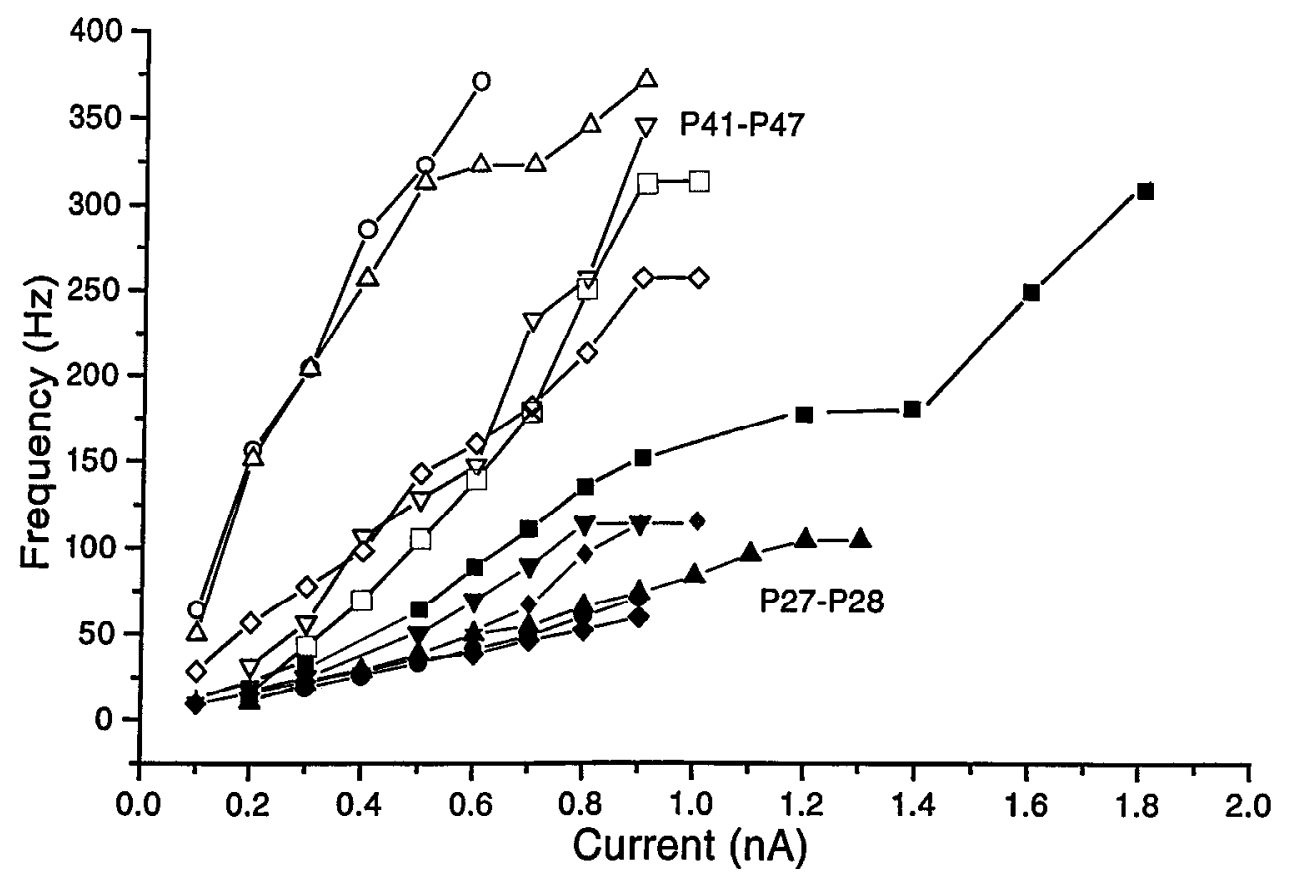

Figure 11. Frequency versus injected current $(f-l)$ relations for PGN neurons at ages P27-28 and P41-47. At P2728 (black symbols), PGN neurons exhibit a relatively shallow $f-I$ relation. In contrast, the $f-I$ relation in $\mathrm{P} 41-47$ (white symbols) PGN neurons was considerably steeper, with PGN cells at this age discharging at frequencies of greater than $250 \mathrm{~Hz}$ with current injections of less than $1 \mathrm{nA}$. examined. Further studies are required to establish the contribution of establishment of relay-nRt/PGN and nRt/PGN-relay connections in the postnatal development of synchronized activity.

The appearance of spontaneous spindle waves at 3-4 weeks of age corresponds to the end of the period during which retinogeniculate axons in the ferret LGNd segregate into the eye-specific laminae and receptive field-specific sublaminae (Linden et al., 1981; Hahm et al., 1991). Recent results have suggested that spontaneous activity in the developing retinogeniculate pathway may be important for the proper development of this connection. In mammals, retinogeniculate segregation into eye- and response property-specific laminae occurs prior to eye opening, indicating that normal visually evoked activity is not necessary for the determination of these anatomical arrangements. However, intraocular infusion of the $\mathrm{Na}^{+}$channel poison tetrodotoxin results in a block of retinal activity as well as a substantial reduction in the segregation of retinal afferents into eye-specific laminae in the LGNd (Archer et al., 1982; Dubin ct al., 1986; Shatz and Stryker, 1988). Similarly, intrageniculate infusion of an NMDA receptor antagonist, APV, results in a decrease in the segregation of retinogeniculate afferents into the ferret LGNd according to receptive-field type (Hahm et al., 1991). These data indicate that spontaneous activity in the retina, and perhaps the subsequent activation of NMDA receptors, is important for the segregation of retinal afferents into their appropriate anatomical comnections with the cells of the LGNd. Indeed, simultaneous recordings from two retinal ganglion cells during the generation of spontaneous action potentials reveal correlated spontaneous activity between neighboring neurons (Galli and Maffei, 1988; Maffei and Galli-Resta, 1990). This correlation between neighboring retinal cells may result from waves of activity that have been observed to sweep across the retina with in vitro preparations of the ferret retina (Meister et al., 1991; Wong et al., 1993).

Our present results suggest that spontaneous or evoked spin dle waves do not develop until approximately 3-4 weeks of age, in other words, after retinogeniculate segregation has occurred. This late development of spontaneous LGNd/PGN activity may be advantageous for the proper development of retinogeniculate connections, since the occurrence of spindle oscillations at earlier ages could disrupt the correlation between spontaneous retinal and thalamic relay cell activity.

We have recently demonstrated with multisite recordings of ferret LGNd in vitro that spindle waves travel across the ferret LGNd slice at a rate of approximately $1 \mathrm{~mm} / \mathrm{sec}$ (Kim et al., 1994). Cross-correlation analysis of simultaneously recorded cells or groups of cells reveals that the degree of correlation between different relay neurons increases as the distance between these cells decreases (U. Kim, T. Bal, and D. A. McCormick, unpublished observations). In this manner, the sweeping of spindle waves through the thalamocortical network could act as a signal of "nearest-neighbor" relations. Presumably, propagation of this signal to the cerebral cortex will follow the dominant synaptic connections between the thalamus, cerebral cortex, and cortical regions. Since spindle waves develop at an age when the precise anatomical relations of thalamocortical and intracortical connections are still being determined through activity-dependent mechanisms (Levay et al., 1978), we propose that the occurrence of these spindle waves may facilitate the estahlishment of appropriate anatomical connections, keeping in mind that sensory input will play a dominant role in the determination of functional connectivity in thalamocortical and corticocortical circuits (reviewed in Shatz, 1990).

\section{References}

Aghajanian GK, Rasmussen K (1989) Intracellular studies in the facial nucleus illustrating a simple new method for obtaining viable motoneurons in adult rat brain slices. Synapse 3:331-338.

Aicardi J (1994) Epilepsy in children. New York: Raven.

Andersen P, Andersson SA (1968) Physiological basis of the alpha rhythm. New York: Appleton-Century-Crofts.

Archer SM, Dubin MW, Stark LA (1982) Abnormal development of kitten retinogeniculate connectivity in the absence of action potentials. Science 217:743-745.

Avoli M, Gloor P (1982) Interaction of cortex and thalamus in spike and wave discharges of feline generalized penicillin epilepsy. Exp Neurol 76:196-217.

Avoli M, Kostopoulos G (1982) Participation of corticothalamic cells 
in penicillin-induced generalized spike and wave discharges. Brain Res 247:159-163.

Avoli M, Gloor P, Kostopoulos G, Naquet R (1990) Generalized epilepsy. Neurobiological approaches. Boston: Birkhauser.

Bal T, McCormick DA (1993) Mechanisms of oscillatory activily in guinea-pig nucleus reticularis thalami in vitro: a mammalian pacemaker. J Physiol (Lond) 468:669-691.

Bal T, von Krosigk M, McCormick DA (1995a) Synaptic and membrane properties underlying synchronized oscillations in the ferret LGNd in vitro. J Physiol (Lond) 483:641-663.

Bal T, von Krosigk M, McCormick DA (1995b) Role of the ferret perigeniculate nucleus in the generation of synchronized oscillations in vitro. J Physiol (I ond) 483:66.5-685.

Buzsaki G, Smith A, Berger S, Fisher LJ, Gage FH (1990) Petit mal epilepsy and Parkinsonian tremor: hypothesis of a common pacemaker. Neuroscience 36:1-14

Cherubini E, Gaiarsa JL, Ben-Ari Y (1991) GABA: an excitatory transmitter in early postnatal life. Trends Neurosci 14:515-519.

Constantine-Paton H, Cline HT, Debski E (1990) Palterned activity, synaptic convergence and the NMDA receptor in developing visual pathways. Annu Rev Neurosci 13:129-154.

Crunelli V, Leresche $\mathrm{N}$ (1991) A role for $\mathrm{GABA}_{\mathrm{B}}$ receptors in excitation and inhibition of thalamocortical cells. Trends Neurosci 14:1621.

Deschênes M, Madagaria-Domich A, Steriade M (1985) Dendrodendritic synapses in cat reticularis thalami nucleus: a structural basis for thalamic spindle synchronization. Rrain Res 334:169-171.

Domich L, Oakson G, Deschenes M, Steriade M (1987) Thalamic and cortical spindles during early ontogenesis in kittens. Brain Res 428 : 140-142.

Dubin MW, Stark LA, Archer SM (1986) A role for action potential activity in the development of neuronal connections in the kitten retinogeniculate pathway. J Neurosci 6:1021-1036.

Fisch BJ (1991) Spehlmann's EEG primer. New York: Elsevier.

Galli L, Maffei L (1988) Spontaneous impulse activity of rat retinal ganglion cells in prenatal life. Science 242:90-91.

Goodman CS, Shatz CJ (1993) Developmental mechanisms that generate precise patterns of neuronal connectivity. Cell 72:77-98.

Hahm JO, Langdon RB, Sur M (1991) Disruption of retinogeniculate afferent segregation by antagonists to NMDA receptors. Nature 351: $568-570$

Horikawa K, Armstrong WE (1988) A versatile means of intracellular labelling: injection of biocytin and its detection by avidin conjugates. J Neurosci Methods 25:1-11.

Hosford DA, Clark S, Cao Z, Wilson WA, Lin F-h, Morisett RA, Huin A (1992) The role of GABA-B receptor activation in absence seizures of lethargic $(\mathrm{lh} / \mathrm{lh})$ mice. Science $257: 398-401$.

Huguenard JR, Hamill OP, Prince DA (1988) Developmental changes in $\mathrm{Na}+$ conductances in rat neocortical neurons: appearance of a slowly inactivating component. J Neurophysiol 59:778-795.

Kellaway P (1985) Sleep and epilepsy. Epilepsia 26:S15-S30.

Kellaway P, Frost JD, Crawley JW (1990) The relationship between sleep spindles and spike-and-wave bursts in human epilepsy. In: Generalized epilepsy. Neurobiological approaches (Avoli M, Gloor P, Kostopoulos G, Naquet R, eds), pp 36-48. Boston: Birkhauser.

Kim U, Bal T, McCormick DA (1994) Spindle oscillations in the ferret LGNd are traveling waves. Soc Neurosci Abstr 20:133.

Kostopoulos G, Gloor P, Pellegrini A, Siatitsas I (1981a) A study of the transition from spindles to spike and wave discharge in feline generalized penicillin epilepsy: EEG features. Exp Neurol 73:43-54.

Kostopoulos G, Gloor P, Pellegrini A, Gotman J (1981b) A study of the transition from spindles to spike and wave discharge in feline generalized penicillin epilepsy: microphysiological features. Exp Neurol 73:55-77.

Levay S, Stryker MP, Shatz CJ (1978) Ocular dominance columns and their devclopment in layer IV of the cat's visual cortex: a quantitative study. J Comp Neurol 179:223-244.

Linden DC, Guillery RW, Cucchiaro J (1981) The dorsal lateral geniculate nucleus of the normal ferret and its postnatal development. J Comp Neurol 203:189-211.
Liu Z, Vergnes M, Depaulis A, Marescaux C (1992) Involvement of intrathalamic $\mathrm{GABA}_{B}$ neurotransmission in the control of absence seizures in the rat. Neuroscience 48:87-93.

Macdonald RL, Olsen RW (1994) $\mathrm{GABA}_{\mathrm{A}}$ receptor channels. Annu Rev Neurosci 17:569-602.

Maffei L, Galli-Resta L (1990) Correlation in the discharges of neighboring rat retinal ganglion cells during prenatal life. Proc Natl Acad Sci USA 87:2861-2864.

McCormick DA, Pape HC (1990) Properties of a hyperpolarizationactivated cation current and its role in rhythmic oscillation in thalamic relay neurons. J Physiol (Lond) 431:291-318.

McCormick DA, Prince DA (1987) Postnatal development of electrophysiological properties of rat cerebral cortical pyramidal neurones. J Physiol (Lond) 393:743-762.

Meister M, Wong ROL, Baylor DA, Shatz CJ (1991) Synchronous bursts of action potentials in ganglion cells of the developing mam malian retina. Science 252:939-943.

Metcalf DR (1970) EEG sleep spindle ontogenesis. Neuropediatrics $1: 428-433$

Mitrofanis J (1994) Development of the thalamic reticular nucleus in ferrets with special reference to the perigeniculate and perireticular cell groups. Eur J Neurosci 6:253-263.

Niedermeyer E (1990) The epilepsies. Diagnosis and management. Baltimore: Urban and Schwarzenberg.

Pirchio M, Lightowler S, Crunelli V (1990) Postnatal development of the $\mathrm{T}$ calcium current in cat thalamocortical cells. Neuroscience 38 : $39-45$.

Ramoa AS, McCormick DA (1994a) Developmental changes in electrophysiological properties of LGNd neurons during reorganization of retinogeniculate connections. J Neurosci 14:2089-2097.

Ramoa AS, McCormick DA (1994b) Enhanced activation of NMDA receptor responses at the immature retinogeniculate synapse. J Neurosci 14:2098-2105.

Shatz CJ (1990) Impulse activity and the patterning of connections during CNS development. Neuron 5:745-756.

Shatz CJ, Stryker MP (1988) Prenatal tetrodotoxin infusion blocks segregation of retinogeniculate afferents. Science 242:87-89.

Snead OC (1992) Evidence for GABA-B mediated mechanisms in experimental generalized absence seizures. Eur J Pharmacol 213:343349

Steriade M, Amzica F (1994) Dynamic coupling among neocortical neurons during evoked and spontaneous spike-wave seizure activity. J Neurophysiol 72:2051-2069.

Steriade M, Contreras D (1994) Relations hetween cortical and thalamic cellular events during transition from sleep patterns to paroxysmal activity. J Neurosci 15:623-642.

Steriade M, Deschênes M (1984) The thalamus as a neuronal oscillator. Brain Res Rev 8:1-63.

Steriade M, Deschênes M, Domich L, Mulle C (1985) Abolition of spindle oscillations in thalamic neurons disconnected from nucleus reticularis thalami. J Neurophysiol 54:1473-1497.

Steriade M, Domich L, Oakson G (1986) Reticularis thalami neurons revisited: activity changes during shifts in states of vigilance. J Neuroscience 6:68-81.

Steriade M, Domich L, Oakson G (1987) The deafferented reticular thalamic nucleus generates spindle rhythmicity. J Neurophysiol 57: 260-273.

Steriade M, McCormick DA, Sejnowski TJ (1993) Thalamocortical oscillations in the sleeping and aroused brain. Science 262:679-685.

Stryker MP, Harris WA (1986) Binocular impulse blockade prevents the formation of ocular dominance columns in cat visual cortex. J Neurosci 6:2117-2133.

von Krosigk M, Bal T, McCormick DA (1993) Cellular mechanisms of a synchronized oscillation in the thalamus. Science 261:361-364.

Wong RO, Meister M, Shatz CJ (1993) Transient period of correlated bursting activity during development of the mammalian retina. Neuron 11:923-938.

Yen CT, Conley M, Hendry SHC, Jones EG (1985) The morphology of physiologically identified GABAergic neurons in the somatic sensory part of the thalamic reticular nucleus in the cat. $J$ Neurosci $5: 2254-2268$. 